\title{
Stage III Hepatocellular Carcinoma AJCC v8
}

National Cancer Institute

\section{Source}

National Cancer Institute. Stage III Hepatocellular Carcinoma A/CC v8. NCI Thesaurus.

Code C134520.

Stage III includes: IIIA: (T3, N0, M0); IIIB: (T4, N0, M0). T3: Multiple tumors, at least one of which is larger than $5 \mathrm{~cm}$. T4: Single tumor or multiple tumors of any size involving a major branch of the portal vein or hepatic vein, or tumor(s) with direct invasion of adjacent organs other than the gallbladder or with perforation of visceral peritoneum. NO: No regional lymph node metastasis. M0: No distant metastasis. (AJCC 8th ed.) 